\title{
Concept formation and art: Further evidence on the applicability of Walk's technique'
}

THOMAS J. TIGHE, Department of Psychology. Dartmouth College, Hanoier, N. H.

The Ss viewed five sets of slides, each set consisting of a different painting by each of the following artists: Picasso, Braque, Leger, Morandi, and Carra. Each set of five slides was presented four times. On the initial presentation $S$ had to guess the name of the artist of each painting. On the next three presentations the $E$ supplied the artist's name for each painting. The percentage of correct classifications on the initial (test) presentations increased progressively from $17 \%$ on the first set of paintings to $60 \%$ on the fifth set.

Walk (1967) has recently described an ingenious technique for investigating the conceptual learning of an artist's style. On a pretest Ss were shown colored slides of a painting by each of the following artists: Cezanne, Degas, Manet, Matisse, Monet, and Renoir. The $S$ was required to guess the painter of each picture as he viewed it, but the names of all artists involved were known to him. This pretest was followed by training in which Ss viewed slides showing four additional paintings by each of these artists with the artist's name supplied for each painting. Then a posttest was given in which 12 slides were presented showing two paintings by each artist (six from the pretest and six new slides), and $S$ was again required to guess the painter of each picture. Concept learning was demonstrated by a marked increase in correct naming of artists for the paintings in the posttest as compared to the pretest. This basic experiment is important since in addition to demonstrating a new technique for the objective study of art, it provides a model for investigating the development of those numerous daily life concepts which lack objective defining criteria.

The present experiment applies Walk's technique with two variations. First, paintings representing the influence of the cubist school were selected for study as being presumably lower on the scale of "meaningfulness" than Walk's sample and therefore as constituting a more rigorous test of the technique. Secondly, the procedure was modified to include a measure of changes in S's ability to conceptualize the artists' styles after each new instance of the concepts was presented, thus providing a more continuous tracking of conceptual development than under Walk's before vs after design.

\section{METHOD}

The artists studied were Picasso, Morandi, Braque, Léger, and Carrà, and the particular paintings of these men which were selected for the experiment are classifiable as falling in the cubist or closely related styles. Reproductions of five different works by each artist were taken from various art periodicals. The artists' names were taped over and Polaroid (black and white) slides were prepared of each reproduction. The five paintings by each artist were as follows. Picasso: Girl with Mandolin; Nude with a Musician; Still Life with Ancient Head; Guitar Player; Student with Pipe. Braque: Woman with Guitar; The Musician's Table; The Portuguese; Violin and Jug; The Marble Table. Morandi: Metaphysical Still Life (1919); Still Life (1916); Still Life (1919); Mannequin on a Round Table; Objects. Carrà: The Metaphysical Muse; The Daughter of the West: Metaphysical Composition; The Engineer's Mistress; Penelope. Léger: The Cup of Tea; Landscape, 1912; Study for the Woman in Blue; Composition with Three Figures; The Balcony. In selecting these paintings an effort was made to avoid similarities of theme within the works of each artist and to include paintings of different structural quality by each artist, e.g., compare Picasso's Nude with a Musician with his Still Life with Ancient Head.

The 25 slides were divided into five sets, each set consisting of one painting by each artist. These sets were then presented to the Ss as five successive paired-associate learning tasks in which $S$ was trained to associate the artists' names with their pictures. Each set of slides was presented four times in the following manner.
First presentation-test trial. Each slide was presented for $5 \mathrm{sec}$ and $\mathrm{S}$ guessed the name of the artist. No information as to correctness of guess was given.

Second presentation-training trial. Each slide was presented for $5 \mathrm{sec}$ and the $\mathrm{E}$ gave the name of the artist at the same time (i.e., $\mathrm{S}$ did not guess on this presentation).

Third presentation-training trial. Each slide was presented for $5 \mathrm{sec}$ and withdrawn. The $\mathrm{S}$ had 5 more sec to write his choice and then the $E$ gave the correct name.

Fourth presentation-training trial. The procedure was the same as in the third presentation.

The $E$ then presented the next four sets of slides in the same fashion. A random procedure was used to select slides for each set and to determine the order in which the sets were presented. The slides within a set were presented in a different order on each of the four presentations. The Ss kept a record of their own responses which was later scored by the $E$.

The Ss were informed each time a set was terminated and a new set begun and they were also informed of the beginning of each new presentation within a set. They were further told that there would always be one and only one picture by each artist in each set. The names of the artists were written on the blackboard and were clearly visible to $\mathrm{Ss}$ throughout the experiment. The Ss-65 college students in an introductory psychology course-were trained in groups of about nine each. Twelve Ss were given post-experimental interviews in which they were asked to state their basis of classification and to describe each artist's style. RESULTS AND DISCUSSION

Definite concept learning occurred. The percentages of correct classifications on the first (test trial) presentation of the five successive sets of slides were $17 \%, 26 \%, 40 \%, 54 \%$, and $60 \%$. This improvement is somewhat better than that observed by Walk who found that accuracy of identification of artists rose from $23 \%$ correct classifications in his pretest to $43 \%$ correct classifications in the posttest. Wide individual differences in performance were observed in the present experiment, ranging from chance performance throughout training to perfect classification over the last two sets. Walk also noted individual differences in the extent to which Ss can utilize the information presented in the training series. It is possible that these differences reflect differences in sensitivity to variables that define artistic style rather than differences in a general conceptual or perceptual learning ability. A simple test of this possibility would be to correlate the performances of Ss under training of this type using artistic vs aesthetically neutral stimuli equated for familiarity.

Without exception, the Ss who were asked to state their basis of classification felt that they relied upon stylistic features rather than upon whatever content cues were available. Also, they indicated that they tended to differentiate the pictures in terms of a global impression rather than through the detection of specific features, and the terms given by these Ss when asked to describe each artist's style were consistent with this statement (e.g., bold, marbelized, suggests motion, thin style, messy, wide open, fuzzy, stormy, jungle-like, airy). There was little agreement across Ss in the use of descriptive terms for a given artist, and direct contradictions in description were common even among successful Ss. Thus, on the basis of this sample, there is little hope that the distinguishing features of artistic style can be isolated through S's reports in such learning experiments. However, it might be possible to experimentally isolate such features by studying concept learning with the present technique under conditions which selectively eliminate or minimize variables hypothesized to be defining features of style. For example, one might compare accuracy of classification with colored vs black and white slides under the hypothesis that some artists use color in a distinctive fashion. Note that in the present experiment there was a significant increase in accuracy of identification despite the fact that the Polaroid slides rendered the stimuli only in black and 
white. However, all the original works were rendered in color and in most cases the artist made extensive use of many vivid colors. It would appear, then, that color, despite its prominence as a cue, is not a necessary distinguishing feature of these artists' styles. It seems likely that variables which might be isolated in this fashion as predictors of a particular artist's style will have the status of probabilistic cues (Bruner, Goodnow, \& Austin, 1956) rather than having an invariant relation with a particular artist.

Finally, it should be noted that the concept formation observed in the present experiment took place with remarkably little training. The entire procedure required only about $25 \mathrm{~min}$. Moreover, with few exceptions the Ss were correct in their guesses on the fourth training trial within each set of slides, and many Ss made correct guesses on the third presentation. This suggests that a more efficient and effective training procedure would be to give fewer training trials and more instances of each artist's work.

\section{REFERENCES}

BRUNER, J. S., GOODNOW, J. J., \& AUSTIN, F. A. A study of thinking. New York: Wiley, 1956.

WALK, R. D. Concept formation and art: Basic experiment and controls. Psychonomic Science, 1967, 9, 237.238.

$$
\text { NOTE }
$$

1. This paper was prepared during a period of support by Public Health Service Research Grant MH1 1088 from the National Institute of Mental Health. 